\title{
Uma conversa \\ com Frederico Simões Barbosa
}

\author{
A conversation \\ with Frederico Simões Barbosa
}

Carlos E. A. Coimbra Jr. 1

\footnotetext{
1 Escola Nacional deSaúde Pública, Fundação Oswaldo Cruz, Rua Leopoldo Bulhões 1480, Rio de Janeiro, RJ 21041-210, Brasil.
}

A história da saúde pública e da epidemiologia no Brasil está intimamente ligada ao desenvolvimento das investigações sobre as grandes endemias infecto-parasitárias. Frederico Adolfo Simões Barbosa é um importante personagem na construção deste campo do saber no país. Tendo iniciado suas atividades de pesquisa na década de 40 , foi um dos primeiros a conduzir estudos epidemiológicos de longa duração no Brasil, seu nome estando estreitamente associado à consolidação da epidemiologia como campo de investigação, tanto na academia como nos serviços de saúde pública.

F. S. Barbosa nasceu em 27 de julho de 1916 em Recife, Pernambuco. Nesta mesma cidade graduou-se em medicina (1938) e em história natural (1952). Especializou-se em parasitologia e em micologia na Universidade de São Paulo, sob a orientação dos professores Samuel B. Pessôa e Floriano de Almeida, respectivamente (1939). Em seguida, obteve treinamento em entomologia médica através de vários cursos e estágios na University of Michigan e Smithsonian Institution. Doutorou-se em medicina pela Universidade do Recife (1942), instituição onde defendeu três Livre-Docências: Parasitologia (1942), Microbiologia (1950) e Medicina Preventiva (1960). Obteve também o título de Mestre em Saúde Pública pela Johns Hopkins University (1946). Ao Iongo de sua carreira ocupou inúmeros cargos acadêmicos em diferentes universi dades, tendo sido professor titular na Universidade Federal de Pernambuco, na Universidade de Brasília e na Escola Nacional de Saúde Pública. Orientou dezenas de teses de mestrado e de doutorado nas áreas da parasitologia, medicina tropical e epidemiologia. Como administrador, dirigiu laboratórios e faculdades em várias instituições brasileiras, incluindo o Centro de Pesquisas Aggeu Magal hães (do qual foi primeiro diretor), a Faculdade de Ciências da Saúde da Universidade de Brasília (1975-76) e a Escola Nacional de Saúde Pública (1985-90). Foi também responsável pelos programas de esquistossomose da Organização Mundial da Saúde em Genebra (1969-71). 
Dentre os tópicos de investigação sobre os quais se debruçou, destacam-se os estudos sobre epidemiol ogia da esquistossomose. Quando iniciou suas pesquisas, havia pouca clareza acerca da determinação e nomenclatura das espécies de moluscos vetoras; a esquistossomose não havia ainda sido tampouco reconhecida como uma endemia importante no Brasil. Neste senti do, as contribuições de F. S. Barbosa ao conhecimento dos vetores, dinâmica de transmissão, epidemiologia e estratégias de controle da esquistossomose foram decisivas.

Como epidemiólogo, sua ênfase foi sempre no campo, na pesquisa realizada na/ com a comunidade. Neste tocante também foi um inovador pois, em uma época quando a maior parte dos estudos era realizada com pacientes em contextos clínicos-hospitalares, F. S. Barbosa desenvolveu estudos de longa duração a nível comunitário. Os artigos que resultaram dessas investigações permitiram um novo olhar sobre a esquistossomose, dimensionando o real peso desta parasitose na determinação dos perfis de morbi-mortalidade nas populações e lançando as bases para os trabal hos de parti cipação popular no controle de endemias.

F. S. Barbosa publicou cerca de 220 artigos em revistas científicas nacionais e estrangeiras, vários capítulos de livro em obras editadas no Brasil e no exterior, além de três livros e inúmeros relatórios técnicos. Em reconhecimento a seu trabalho, recebeu várias honrarias, como a Medalha Cultural Pirajá da Silva, Professor Honoris Causa pela Universidade de Brasília e pela Escola Nacional de Saúde Pública, além de ter tido duas espécies de insetos e outra de trematódeo nomeadas em sua homenagem: Culicoi des barbosai (Wirth \& Blanton, 1956), Sepedonea barbosai (Knutson \& Bredt, 1976) e Echinostoma barbosai (Lie \& Bash, 1966).

Nesta entrevista não tive a intenção de ser exaustivo no que se refere à cobertura da vida e da obra de Frederico Simões Barbosa. Procurei enfocar alguns períodos de sua formação que considerei particularmente relevantes para compreender sua trajetória intelectual e, obviamente, em sua produção científica, principalmente no que se refere aos seus estudos em epidemiologia da esquistossomose. A entrevista foi realizada em duas etapas (maio ejunho de 1996) em seu apartamento em Boa Viagem, Recife.

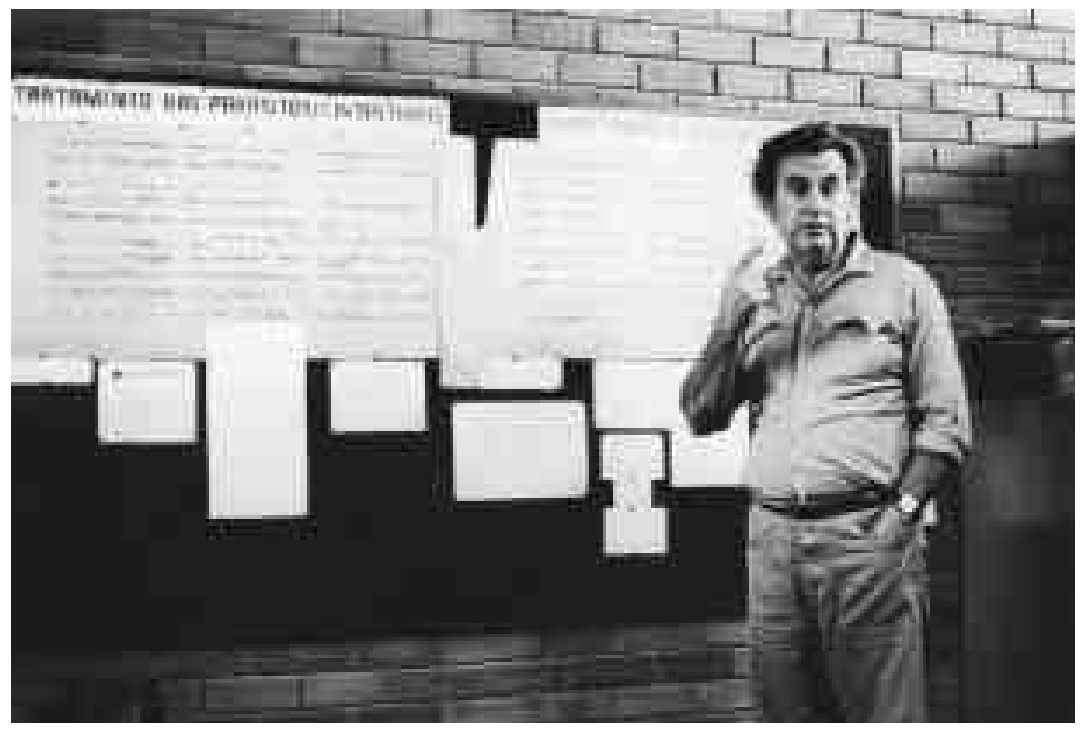

Frederico Adolfo Simões Barbosa: Programa de Medicina Comunitária, Planaltina, Distrito Ferderal,1976.(cortesia: Centro de Pesquisas Aggeu Magalhães/Fiocruz). 
Coimbra Fale-nos um pouco sobre o início de sua carreira, sua opção pela medicina e de sua vida estudantil.

Barbosa Eu meformei em 1938, com 22 anos, e nessa época ainda não existia a universidade. O que tínhamos era a Faculdade de Medicina do Recife, uma instituição privada composta de professores selecionados no próprio meio pernambucano. Era uma faculdade que dispunha de poucos recursos, na qual os estudantes pagavam um taxa (não a exorbitância de hoje) e os professores ganhavam muito pouco. Esta faculdade tinha a área clínica bem desenvolvida, de formação alemã e francesa. Minha decisão de estudar medicina foi mais por influência paterna. Meu pai e meu avô foram grandes clínicos. Intimamente eu sabia que não tinha vocação para a clínica médica e pretendia fazer ciências biológicas, que na época se chamava história natural. Contudo, meu pai não concordou com minha ida para São Paulo para estudar biologia e eu então acabei estudando medicina, mas sempre com uma visão biológica dos fenômenos. Segui então a carreira, trabaIhando no laboratório de análises clínicas do Hospital do Centenário, criado por meu pai, e que hoje pertence ao Instituto de Previdência dos Servidores do Estado. Foi a forma que encontrei para escapar da clínica, que eu achava entediante.

C Como era o ambiente acadêmico em Recife? Que estímulos havia para um estudante de medicina seguir carreira científica?

B Contávamos com poucos recursos e não havia um ambiente acadêmico propriamente dito. Tampouco havia estímulos para que se seguisse carreira científica. Comigo aconteceu um fato fortuito que marcou minha vida. Foi a vinda de Samuel Pessôa a Recife para ministrar um curso de parasitologia médica. Isto aconteceu antes de eu me formar, em 1936. O curso foi excelente e, pela primeira vez, tive um contato realmente íntimo com o professor Samuel Pessôa. Sua visita foi muito importante e logo começamos a trabalhar. Fundamos então a Sociedade Pernambucana de Biologia, muito pequena, congregando estudantes e professores jovens, e formamos um pequeno grupo para trabal har em parasitologia. Nessa época, chegamos a publicar alguns artigos, eu ainda como estudante.

C Como foi sua vivência com Samuel Pessôa? B Samuel era uma pessoa extremamente extrovertida, tinha um carisma fantástico e conduzia o trabalho com muita liberdade dentro do laboratório. Era um scholar de fato. Ele foi o formador de uma Escola, uma figura realmente extraordinária.

C Antes dessa visita de Samuel Pessôa havia al gum trabalho de pesquisa na Faculdade que contemplasse a parasitologia ou foi a vinda dele que realmente estimulou o início desses estudos em Pernambuco?

B Foi a vinda de Samuel, porque a área de ciências básicas na Faculdade era muito pobre. Havia o laboratório de anatomia patológica do professor Aggeu Magalhães que fazia alguns trabal hos em patologia de doenças endêmicas, como a esquistossomose. Era talvez o único laboratório mais ativo em pesquisa, tendo como assistentes Barros Coelho, Aggeu Magal hães FiI ho e outros. Mas foi Samuel Pessôa quem me despertou para a parasitologia. Esta importante iniciativa partiu do professor Argênio Tavares, cirurgião, que, como amigo de Samuel Pessôa, foi quem promoveu sua vinda. Foi também o professor Tavares quem conseguiu com Assis Chateaubriand, dos Diários Associados, bolsas de estudos em São Paulo para seis estudantes pernambucanos se especializarem nos diferentes campos das ciências básicas. Lembro-me ainda de alguns nomes que, além de mim, participaram desse treinamento: Wladimir Lobato Paraense, Durval Lucena e outros. Destes seis, apenas eu e Durval retornamos à Recife. Para mim foram dois anos de muito trabalho em São Paulo, estudando parasitologia sob a orientação de Samuel Pessôa e micologia sob Floriano de Almeida. Um dos pedidos da Faculdade foi de que eu também fizesse um estágio em micologia pois, nesta época, não havia nenhum micologista em Recife. Então eu assumi este compromisso. Apesar de ter ficado mais tempo na parasitologia, meus primeiros trabalhos de investigação acabaram sendo em micologia. Ao retornar a Recife fui muito solicitado no sentido de prestar serviços à dermatologia. Montei um laboratório de micologia na Faculdade de Medicina e dava apoio à dermatologia, na época com o professor Jorge Lobo, que descreveu a blastomicose queloidiana ou lobomicose. Durante esse período cheguei a publicar alguns trabalhos em micologia e em entomologia. Era o que eu podia fazer na ocasião face à falta de estrutura, de recursos e de ambiente mesmo.

C Dentre seus trabalhos em micologia, qual teve mais impacto?

B Foi o trabalho que discutiu a posição taxionômica de Paracoccidi oides brasilensis, apesar de o mesmo ter sido publicado numa revista regional, de pouca circulação ${ }^{1}$. Este estudo foi 
motivado a partir de uma si tuação de conflito que existiu entre Floriano de Almeida, de São Paulo, e Olympio da Fonseca, do Instituto Oswaldo Cruz, no Rio de Janeiro. Nessa época havia muita confusão com respeito à sistemática destes fungos, e Olympio da Fonseca pretendeu criar um novo gênero - Lutziomyces. Os trabalhos de Floriano de Al meida foram fundamentais para determinar a especificidade do fungo da paracoccidioidomicose, distinguindo-o dos agentes etiológicos da coccidioidomicose e da blastomicose norte-americana. Eu então tomei a posição de Floriano de Almeida e publiquei um artigo que ajudou a compreender a questão da nomenclatura deste fungo, defendendo a validade do gênero Paracoccidioides e demonstrando o equívoco do professor Olympio da Fonseca.

C Como o clima político dessa época influenciou seu trabalho?

B Há fatos pessoais que me levaram a sair de Pernambuco e que influíram sobre os rumos de minha atuação profissional. Nos anos 30 tivemos a ditadura de Getúlio, tão sangrenta quanto a segunda ditadura ocorrida no país, nos anos 60 . Nós, estudantes, fizemos uma reação muito grande e eu fiquei em evidência, porque meu pai foi muito visado durante esse tempo pela ditadura local, encabeçada por Agamenon Magalhães, irmão de Aggeu MagaIhães que, por sinal, não se davam muito bem. As perseguições foram muito grandes, e meu pai chegou a ser preso durante uma semana, vindo a ser liberado graças a injunções de amigos. Em virtude desses acontecimentos, eu e meu irmão tivemos de sair de Pernambuco. Eu sai antes de me formar, em 1938. Posteriormente, tive de voltar escondido a Pernambuco para me formar. Em 24 horas consegui fazer os exames finais e, na secretaria da Faculdade, colei grau. Feito isso, voltei imediatamente a São Paulo, já com a bolsa oferecida pelos Diários Associados.

C Quando o senhor retornou a Recife?

B Até o fim do governo de Agamenon MagaIhães fiquei entre o Rio e São Paulo. Com a 2a Guerra Mundial, para poder voltar a Pernambuco, alistei-me como voluntário no serviço militar. Como oficial do Exército eu tinha imunidade, não podendo ser preso. Foi quando servi no Hospital Militar de Recife, até 1945. Nesse ano consegui uma bolsa de estudos do Institute of Interamerican Affairs, através do SESP (Serviço Especial de Saúde Pública), e passei os anos de 1945 e 1946 nos E.U.A. fazendo mestrado em saúde pública em Johns Hopkins.
Aproveitei essa época para cursar, durante as férias de verão, um curso de limnologia e outro de entomologia na estação biológica da Universi ty of Michigan, próxima aos Grandes Lagos. Quando voltei ao Brasil a ditadura de Getúl io já agonizava e fui trabalhar como professor assistente de parasitologia na Faculdade de Medicina, onde também ensinava micologia.

C Um fato que chama a atenção em sua trajetória é a sua produção. O senhor publicou muitos artigos durante esse período, apesar de jovem. Como era a questão do "publicar" nessa época?

B É difícil dizer. Eu tinha uma inclinação para a produção intelectual, na área da parasitologia que foi muito estimulada pelo grupo do Samuel Pessôa. É verdade que, naquela época, poucos pesquisadores publicavam com regularidade. Não havia estímulo financeiro ou pressão de qualquer natureza. Por outro lado, as limitações financeiras que marcaram o início da minha carreira fizeram com que eu me limitasse mais à sistemática, apesar de nunca ter sido muito amigo desse tipo de trabalho. Mas acabei trabalhando na sistemática de fungos e de insetos. Este tipo de material estava mais facilmente ao alcance de minhas mãos e eu não precisava de maiores recursos ou equipamentos para estudá-lo. Os trabalhos de campo acabavam sendo ban cados com meus próprios recursos. Viajei muito ao interior para coletar $\mathrm{Cu}$ licoides, gênero de Ceratopogonídeos, e recebia também material de outros pesquisadores. Havia muito intercâmbio. Aqui mesmo em Boa Viagem, próximo a minha atual residência, eu montei armadilhas em alguns mangues, que hoje não mais existem, e as vistoriava mensalmente. Foi meu primeiro estudo de população. Os resultados desses estudos foram publicados em uma revista local de modo que não tiveram muita repercussão. Mas, como quem trabalhava com Culicoides formava um grupo muito pequeno, o intercâmbio era intenso e havia muita troca de separatas. Nessa época a troca de separatas era muito importante.

C Vê-se na sua bibliografia um salto meio abrupto entre o que se poderia chamar de primeira fase, dominada pela micologia e entomologia médica, e segunda fase, dedicada à malacologia médica, e que o encaminhou aos estudos sobre epi demiologia da esquistossomose. Essa transição coincide com sua ida para o então recém-criado Centro de Pesquisas Aggeu Magal hães. Fale-nos um pouco sobre esse momento. 
B Meu interesse pela esquistossomose deuse a partir da criação do Centro de Pesquisas Aggeu Magalhães, em 1950. Este centro foi fundado pelo conhecido sanitarista Amílcar Barca Pellon que, no início dos anos 40, realizou um trabalho monumental para aquela época - o exame coproparasitológico de quase meio miIhão de pessoas - que trouxe importante contribuição ao estudo da esquistossomose no Brasil $^{2}$. Pela primeira vez determinou-se a extensão da área endêmica da esquistossomose no país, tendo sido reveladas taxas de infecção que surpreenderam o mundo da saúde pública da época. A partir da publicação deste trabaIho, Barca Pellon conseguiu verbas para a construção do primeiro centro de pesquisas em doenças endêmicas do país, a ser instalado em Recife.

Barca Pellon e Aggeu Magalhães eram muito amigos e, possivelmente, este último viria a ser o primeiro diretor do Centro, caso não tivesse fal ecido pouco antes do término da obra. Com isso fui indicado para dirigir o Centro, não sei bem por que, mas creio que por influência do sanitarista pernambucano Gilberto da Costa Carvalho. Havia um problema, no entanto, com relação à minha indi cação para este cargo. Eu não era pessoa benquista por causa de minhas posições políticas, particularmente no que se referia ao governo de Agamenon MagaIhães. Na época, o governador era Barbosa Lima Sobrinho que, apesar de ter sido apoiado por Agamenon, sempre fora uma pessoa independente, como ainda o é até os dias de hoje. O governo federal não nomeava sem consulta aos políticos locais, mas Lima Sobrinho apoiou minha indicação.

Foi por isso que mudei de ramo, pois o objetivo do Centro, segundo Barca Pellon, era claro, no sentido de estudar as endemias regionais, com particular atenção à esquistossomose. Tratava-se do que poderíamos chamar de um centro de pesquisas aplicadas. Como, a partir do trabalho de Barca Pellon, a esquistossomose havia saído vitoriosa, concentramonos nesta endemia. Eu não tinha nenhuma experiência com esquistossomose. Na verdade, pouco se conhecia sobre a esquistossomose na época, inclusive no que se referia ao parasita e às espécies de transmissores. Havia poucos trabalhos publicados no Brasil, destacando-se os de Lutz, que realizou estudos sobre planorbídeos, tendo inclusive visitado o nordeste e realizado coletas de caramujos. Contudo, a sistemática era ainda baseada na concha e as espécies vetoras estavam mal definidas. Conheciase muito pouco sobre anatomia interna, morfologia, biologia e ecologia desses moluscos.
Resolvemos que partiríamos do início, estudando o caramujo e o parasita.

C No que se refere à epidemiologia da esquistossomose, era prioridade na época o estudo taxionômico dos planorbídeos?

B Sim, pois de fato nós desconhecíamos os vetores, inclusive sua nomenclatura. Eu comecei a partir daí e, se você revir meus trabalhos, verá que comecei com a sistemática, depois passei para a biologia, a ecologia de moluscos e só depois iniciei os estudos de epidemiologia propriamente ditos.

C Mais ou menos nessa época começaram a surgir vários trabal hos em taxionomia de planorbídeos, havendo inclusive certa polêmica entre os malacologistas. Como foi a evolução desses trabalhos?

B Eu não me defino como uma taxionomista, nem nunca fui um morfologista propriamente dito. Como disse, entrei neste campo mais pelo compromisso que assumi no Centro e não podia deixar de fazer sistemática de moluscos. Alguns anos depois entrava em cena como malacologista o Dr. Wladimir Lobato Paraense, que fez estudos minuciosos nesse campo, e eu então me senti, gradativamente, desligado dessa área, podendo dedicar-me a outros aspectos que me interessavam mais como, por exemplo, os estudos sobre potencial de transmissão de moluscos de diferentes regiões do Brasil e de outros países da América Latina (Cuba, Chile, Paraguai, etc.). Nessa época, participei de dois estudos financiados pela OPAS e que contaram com a colaboração de Louis Olivier e Charles Dobrolvony. Foi quando começamos a trabaIhar com moluscicidas que, naquela época, eram tidos como o meio mais importante de controle da esquistossomose. Olivier era um ecólogo e, juntos, publicamos diversos artigos sobre ecologia dos vetores da esquistossomose.

C Dentre seus estudos sobre a biologia de moluscos aquáticos, são muito citadas suas observações sobre a dormência do caramujo e de sua capacidade de manter a infecção dentre as mais importantes desta série de investigações ${ }^{3}$. Fale-nos mais sobre estes trabalhos.

$B$ A verdade é que sempre chamou-nos atenção a capacidade que estes moluscos tinham para sobreviver fora d'água. Alguns chegavam a sobreviver por 3-4 meses nestas con dições, tanto no campo como no laboratório. Imaginamos então o que poderia ocorrer com os caramujos infectados sob condições de dessecação. Verificamos que as fases larvárias do Schistosoma mansoni entravam também em um proces- 
so de diapausa ou dormência, isto é, verificava-se uma parada de crescimento do parasita dentro do molusco. No campo isso ocorria da mesma maneira. Caramujos dessecados encontrados sob o solo, quando colocados em água, após al guns dias, eliminavam cercárias.

C No campo da ecologia, foi o seu trabalho realizado na periferia de Recife $^{4}$ o primeiro a tratar da competição entre espécies do gênero Biomphalaria?

B Sim, essa foi a primeira observação sobre competição entre moluscos deste gênero, realizada sob condições que se poderia chamar de um "experimento natural".

C De onde veio esta idéia? Na época nenhum artigo publicado tratava de competição neste gênero.

B A constatação empírica, já antiga, é que duas espécies de Biomphalaria não eram habitualmente encontradas no mesmo criadouro. No Nordeste, por exemplo, glabrata e straminea existiam na mesma região, mas em criadouros diferentes. Nesse estudo partimos da teoria segundo a qual duas espécies que ocupam o mesmo nicho ecológico não co-habitam um mesmo criadouro. Durante três anos o que vimos no campo foi a gradual substituição de B.glabrata por B.straminea que, apesar de terem produzido híbridos, estes não se mantiveram sob condições naturais. Muitos anos depois desenvolvemos um modelo experimental de estudo em laboratório e em campo que confirmou a superioridade competitiva de B.straminea sobre B.glabrata ${ }^{5}$.

C No campo da malacologia médica, quais são os pesquisadores que o senhor listaria como tendo sido seus parceiros na comunidade científica? Havia muitas disputas?

B Eu não tive muitos problemas de disputa ou oposição. No exterior trabalhei em colaboração com vários pesquisadores, como Louis Olivier, Emile Malek e Elmer Berry, dos E.U.A., Christopher Wright, da Inglaterra, e Bengt Hubendick, da Suécia. O meio acadêmico nacional era muito reduzido e eram poucas as pessoas que trabalhavam em esquistossomose. 0 problema maior ocorreu com a oposição de um grande malacologista, o Dr. Wladimir Lobato Paraense, pois, em dois momentos distintos, nossos trabalhos conflitaram.

C O senhor poderia falar mais sobre estes episódios?

B Em uma oportunidade, de passagem por Lisboa, vindo de Paris, visitei o Instituto de Me- dicina Tropical naquela cidade, onde havia uma coleção de moluscos vivos. Como todo malacólogo, também tinha a vaidade de ter em minha coleção espécimens de outras regiões. Era a Biomphal aria pfeifferi que eu ainda não tinha. Pedi então ao diretor do instituto alguns exemplares desta espécie e fui prontamente atendido. Ele então disse que, há poucas semanas, também havia passado pelo instituto o Dr. Paraense, que pediu uma amostra do mesmo molusco. Como não tinha o interesse imediato em estudá-los, apenas queria ter uma pequena criação, deixei-os de lado e só me interessei realmente por eles quando saiu publicado um artigo de Lobato colocando esta espécie em sinonímia de Biomphalaria straminea, sob a designação de Taphi us pfeifferi. O trabalho estava muito bem feito, demonstrando uma identidade morfológica entre os dois e também o intercruzamento com a produção de híbridos férteis. No entanto, achei tudo muito estranho e suspeitei da possibilidade de que pudesse ter havido mistura acidental das duas espécies nos aquários do laboratório de malacologia em Lisboa. Mandei então buscar na África exemplares de B. pfeifferi obtidos nos mesmos locais onde a espécie havia sido descrita pela primeira vez. Ao examiná-los, constatei que eram completamente diferentes de B. straminea e não cruzavam. Publiquei então um trabalho contestando o artigo de Paraense e imagino que isto deva ter produzido um certo desapontamento nele $\mathrm{e}^{6}$.

Outra grande disputa foi gerada a partir de um trabalho de grupo, envolvendo parceria com vários malacólogos estrangeiros, e que tinha como objetivo colocar ordem na então confusa sistemática da família Planorbidae. Sabíamos que Tropicorbis e Australorbis não poderiam se manter como gêneros diferentes. De repente Lobato publicou um trabalho reinvidicando a unificação destes gêneros sob o gênero Taphius. Era uma decisão que não poderia ter sido tomada isoladamente, por ser de muito peso internacional. Passei então 30 dias em Londres trabal hando na coleção do Museu Britânico, acompanhado por C. Wright, examinando os tipos e toda a literatura. Concluímos que outros nomes eram na verdade mais antigos do que Taphiuse que poderiam ser utilizados para abranger este grupo de moluscos. Publicamos então um trabalho - eu, Wright, Hubendick e Malek - contestando o gênero Taphius e propondo Biomphalaria (que não era o nome mais antigo) como único gênero de moluscos planorbídeos vetores da esquistossomose mansônica, tanto na África como nas Américas, e que até então vinham sendo designados 
sob diferentes nomes, causando muita confusão ${ }^{7}$. Pensamos muito também nas implicações de ordem prática que poderiam advir da modificação brusca de um nome já consagrado, em particular por se tratar de um grupo de vetores de tamanha importância. As próprias regras de nomenclatura internacional contemplam a possibilidade de, quando o uso de um nome é consagrado e se refere a um organismo de importância econômica, poder-se pedir a suspensão da regra de prioridade. O Comitê Internacional de Nomenclatura Zoológica acatou o nosso pleito, e o Lobato ficou numa situação difícil, isolado.

C Houve um período durante o qual, simultaneamente, o senhor trabalhava com ecologia/biologia de moluscos e epidemiologia/ controle da esquistossomose em populações humanas. Pontezinha foi a primeira comunidade onde o senhor trabalhou?

B Sim, vocêtem razão. O trabal ho em Pontezinha levou cerca de seis anos e foi o primeiro estudo de comunidade, longitudinal, em esquistossomose 8 . Outra investigação de campo, avaliando a eficácia de moluscicidas, durou cerca de 12 an os $^{9}$. Antes de Pontezinha, no entanto, eu já vinha investigando a esquistossomose em populações humanas. Iniciei com meu estudo para a cátedra de medicina preventiva, comparando a morbidade na esquistossomose em quatro localidades endêmicas no estado de Pernambuco ${ }^{10}$. Portanto, é verdade, estávamos fazen do várias coisas simultaneamente. Eu já desconfiava que os moluscicidas não tinham tanto valor no controle da esquistossomose. Foi uma grande luta minha, principal mente quando cheguei em Genebra, onde os moluscicidas eram considerados como de muito valor no controle da esquistossomose. Havia interesses de certas empresas e da própria OMS no sentido de difundir o uso desses químicos. Em Pontezinha não se usou moluscicida nem houve ênfase em tratamento de doentes. Na época o produto disponível era o antimônio, uma droga muito tóxica. Quando iniciamos os trabalhos nessa localidade houve inclusive um óbito associado ao uso desta droga. Suspendi então a quimioterapia e comecei a trabalhar enfatizando saneamento e desenvolvimento comunitário. Com isso consegui reduzir a esquistossomose na área a níveis bem baixos. A comunidade respondeu muito bem ao trabalho. Saneamos toda a região construindo fossas, etc. Depois de Pontezinha realizei outro trabalho que envolveu quatro comunidades da Zona da Mata em Pernambuco. Este trabal ho também durou uns cinco anos.
C Parece-me que, para a época, sua estratégia foi muito inovadora. Como foi o impacto de seu trabal ho na comunidade científica?

B De fato, o trabalho em Pontezinha foi vanguarda porque, na época, estavam todos olhando apenas para o controle químico. Contudo, não recebeu muito crédito, principalmente no exterior. A ênfase das pesquisas centrava-se mais no vetor e/ ou no parasita. TrabaIhos de comunidade não gozavam de muito prestígio. Acho mesmo que este foi o primeiro estudo que se preocupou realmente em trabaIhar com a comunidade a questão do controle de uma endemia.

C Como era constituída sua equipe? Havia outros epidemiologistas?

B Não, eu era só. Na realidade tínhamos um número muito limitado de pesquisadores e predominavam os trabalhos em parasitologia e patologia. No campo contei com três assistentes sociais. Foi a Hortência Holanda, educadora do Ministério da Saúde, quem me colocou à disposição três moças, que fizeram um trabalho excelente, praticamente viveram na comunidade. Também tive bons técnicos de laboratório que me auxiliavam em praticamente tudo.

C Fale-nosum pouco sobre sua pesquisa sobre epidemiologia da esquistossomose, condições de saúde e produtividade dos cortadores de cana- de-açúcar em Catende ${ }^{11}$. É um trabaI ho muito citado até hoje.

B A pesquisa em Catende foi o primeiro estudo clínico-epidemiológico realizado no campo, na comunidade. Até então, todos os estudos eram realizados em hospitais e limitavam-se à apresentação de tabelas de casuísticas segundo as principais formas clínicas da doença. As questões levantadas neste estudo em Catende remetem a uma série de perguntas que já nos fazíamos sobre o peso econômico da esquistossomose. $\mathrm{Na}$ época só conhecíamos outros três ou quatro estudos realizados na África com esta abordagem. Nosso trabalho mostrou que os portadores de formas graves de esquistossomose têm uma redução de produtividade da ordem de $35 \%$. Chegamos também a fazer uma estimativa da perda econômica para o Estado de Pernambuco ocasi onada pela esquistossomose. Nesta época havia certa falta de mão-deobra nos engenhos devido às migrações para o sul do país. Isto despertou muito o interesse dos donos de engenho e do governo local para o problema da esquistossomose no Estado.

C Chama minha atenção a sua capacidade de ter conduzido, simultaneamente, dois ou três 
projetos de longa duração, envolvendo estudos em biologia/ ecologia do molusco, epidemiologia da endemia em comunidades e estratégias de controle.

B Bom, eu tive certas facilidades no Centro e bons financiamentos, principalmente do exterior. Eram trabalhos caros, realizados Ionge de Recife, e que requereram recursos de várias fontes. Por outro lado, contei com equipes muito bem treinadas, tanto no campo como no laboratório. De minha parte, vivia tempo integral para a pesquisa quando ainda não havia esta categoria no plano de carreira acadêmica.

C Qual era o seu segredo para conseguir tantos financiamentos do exterior?

B Em parte o meu relacionamento com pesquisadores no exterior e com o grupo da OMS, além da constância de minhas publicações. Antigamente, o National Institutes of Health, que foi a instituição que me concedeu mais recursos para pesquisa, tinha um programa especificamente voltado para outros países. Além disso apoiavam projetos de longo prazo.

C E sobre sua experiência nos E.U.A., de que maneira contribuiu para o seu crescimento pessoal?

B Representou muito. Primeiro a vivência no exterior, a oportunidade de ter freqüentado um centro de renome como Johns Hopkins, para o estudo da saúde pública. Foi muito importante também para abrir meus horizontes para o campo do social na saúde pública. Naquela época as contradições sociais já eram muito grandes nos E.U.A., particularmente no que se refere à questão racial . Eu vivi perto de uma comunidade negra e assi sti a discriminação racial, o que me levou a refletir sobre o tema da discriminação também em nosso país.

C Fale-nos de sua experiência em Genebra, na Organização Mundial da Saúde.

B Foi em 1969, quando aceitei o convite que já me haviam feito umas três ou quatro vezes para assumir um cargo na OMS. Nessa época pude me aposentar da Faculdade e do Ministério da Saúde, e o cenário político do país neste período levou-me a decidir a passar um tempo fora. Fui com um contrato de dois anos e, na unidade de doenças parasitárias, era o responsável pelo programa de esquistossomose e demais doenças transmitidas por moluscos. A experiência na OMS foi extremamente rica. Genebra era como se fosse um corredor do mundo. Toda a informação e todos acabavam passando por lá. Também era um trabalho político de muita responsabilidade. Meus relatórios normalmente eram carimbados como confidenciais. Contudo, tive uma relação muito difícil com meu diretor. Ao final, não quis renovar o contrato e preferi retornar ao Brasil, inclusive porque já tinha um convite para Brasília e outro para Belo Horizonte.

C Que pontoso senhor destacaria de seu período na OMS?

B Bem, a OMS é um órgão extremamente político. Havia muita pressão por parte de certas empresas. Por exemplo, naquela época havia grande interesse no uso de moluscicidas que, quase sempre, eram preconizados como medida única de controle. Opus-me a colaborar com esse esquema e cheguei a ser muito pressionado para dar pareceres, etc. A Bayer produzia o Bayluscide, e o governo brasileiro chegou a comprar não sei quantas toneladas do produto, que ficaram a apodrecer por aí, nos porões da burocracia. Vendia-se Bayluscide ao mundo inteiro. Nessa época, um pesquisador egípcio muito conhecido - M. Farooq - chegou a publicar, em um mesmo número do Boletim da OMS, uns quatro ou cinco trabalhos seguidos exaltando o Bayluscide no controle da esquistossomose. Acontece que eu já havia trabalhado com moluscicidas no Brasil, em um estudo de dez anos de duração realizado em São Lourenço da Mata, e duvidava de sua factibilidade. Isso porque, apesar do uso continuado, o Bayluscide não interrompeu a transmissão na região. Além disso, as dificuldades de aplicação, o custo elevado e o impacto ambiental levavam-me a ver que as tantas dificuldades inerentes ao controle químico eram de difícil resolução. Por isso era contra, salvo em situações muito particulares.

Aconteceu que, nesse momento, o governo egípcio pediu à OMS que enviasse uma comissão técnica capaz de avaliar o trabal ho de Farooq. Era uma situação muito delicada. Acabamos indo eu, representando a OMS, o professor H. M. Gilles, da Liverpool School of Tropical Medicine, e uma equipe de pesquisadores egípcios indicados pelo próprio governo. Trabalhamos por cerca de 30 dias revendo papéis referentes à pesquisa de campo conduzida por Farooq, em uma região próxima a Alexandria. Saiu então um trabalho mostrando a incoerência dos resultados de Farooq ${ }^{12}$. Este nosso artigo representou um duro golpe nos que defendiam o controle químico.

C Poderíamos dizer que o projeto que o senhor coordenou em Planaltina (Distrito Federal), como professor da Faculdade de Ciências da Saúde da Universidade de Brasília, foi o que 
envolveu o maior número de pesquisadores associados e sub-projetos?

B Sem dúvida. Foi o projeto maior e melhor financiado que coordenei, contando com vários convênios e recursos advindos da Kellogg Foundation, Inter-American Foundation, Funrural e Fundações Hospitalar e do Serviço Social do Distrito Federal.

C Por que Planaltina?

B Bem, fui atraído por Brasília, apesar de sua situação política complicada. O reitor nessa época era extremamente comprometido com a direita, o que nos trouxe muitas dificuldades. O que me atraía na UnB era a base inovadora sobre a qual foi assentada a Faculdade de Ciências Médicas (posteriormente chamada Faculdade de Ciências da Saúde). A Faculdade foi montada com um sentido comunitário muito avançado para a época, tendo como base oHospital Comunitário de Sobradinho. Chegando a Brasília, pensei em retomar o trabalho de Sobradinho, que havia sido destruído pelas tantas ingerências políticas que sofreu. Mas a população estava muito cansada e eu, então, preferi uma área nova, daí Planaltina, que fica relativamente próxima de Sobradinho. A idéia era sensibilizar alunos e professores para a discussão em torno de um novo modelo de medicina comunitária que contemplasse a interação docente-assistencial. O programa durou cerca de 4-5 anos, quando foi abruptamente interrompido pela reitoria. Eu estava retornando de uma viagem ao exterior quando encontrei o projeto destruído. O próprio reitor escreveu às agências de financiamento comunicando o seu cancelamento unilateralmente, sob a desculpa de que estavam fazendo uma reforma do ensino médico na faculdade.

C Apesar destes reveses, qual foi o saldo da experiência de Planaltina para a pesquisa, ensino e organização de serviços de saúde?

B Apesar do tempo ter sido curto, acho que muitos aprenderam conosco a trabalhar em comunidades. Tivemos a adesão total do Hospital de Planal tina e acho que o maior ganho foi no campo do ensino. Criamos um sistema de ensino paralelo na Faculdade, através da oferta de várias disciplinas optativas para as quais orientávamos os alunos interessados em saúde pública. Depois criamos o internato ea residência em medicina preventiva. Houve pouco tempo para pesquisa, mas, assim mesmo, saíram alguns trabalhos sobre a estruturação do programa e análise dos serviços de saúde ${ }^{13}$ e estudos sobre condições de saúde da comunidade ${ }^{14}$. Também foram apresentadas duas teses de mestrado ${ }^{15}$ e várias comunicações em congressos. Mas reitero que o tempo para pesquisa foi curto. Ao final, consegui recursos com o CNPq para fazer a avaliação geral do programa e publicar um relatório final ${ }^{16}$.

C Por fim, gostaria que nos falasse de seu trabalho como editor e consultor de diferentes revistas científicas no Brasil e no exterior.

B Minha primeira experiência mais sólida neste campo foi em Recife, quando passei a editar as Publicações Avul sas do Centro de PesquisasAggeu Magalhães, ainda nos anos 50 . Esta série foi criada com o objetivo de permitir a publicação rápida dos resultados de nossas pesquisas, numa época em que no Brasil não havia muitas opções para publicar. Seguíamos mais ou menos o formato do que os americanos chamavam "occasional papers" que tinham a vantagem de não impor os limites de espaço que normalmente se observam nas grandes revistas. A desvantagem é que a divulgação era restrita e acho que hoje seria muito difícil manter uma publicação desse tipo, pois existem meios melhores. Naquela época trocávamos separatas e éramos poucos. No mundo inteiro éramos uns 20 ou 30 trabal hando com esquistossomose. Depois acabamos interrompendo esta série, um pouco até por pressão do Ministério da Saúde, que vinha editando a Revista Brasileira de Malariologi a e Doenças Tropicais e nos pressionava pois nunca publicávamos lá. Além do que eu mesmo já estava publicando mais em inglês, em revistas estrangeiras. Participei ativamente do conselho editorial de várias revistas como a da Soci edade Brasileira de Medicina Tropical e as Memórias do Instituto Oswal do Cruz. Por fim, juntamente com um grupo da ENSP, fundamos os Cadernos de SaúdePública, que hoje vejo tão bem estabelecido.

C Muitas vezes ouve-se o comentário de pesquisadores associados a instituições em países do "terceiro mundo" de que há discriminação por parte dos editores de revistas do dito "primeiro mundo". Como foi no seu caso?

B De modo geral nunca tive problemas com meus artigos. Certa ocasião tentei publicar na Science. Enviei dois trabalhos que foram recusados e, da terceira vez, consegui que um deles fosse aceito. De outra vez tentei publicar em Ecology - tive um trabalho recusado e outro consegui publicar. Também consegui publicar nas principais revistas em medicina tropical e parasitologia editadas nos E.U.A., na França e na Inglaterra. Acho que, em geral, os editores eram muito cuidadosos no sentido de devolver cópias com críticas indicando correções a se- 
rem feitas, etc. Não posso dizer que tenha sido discriminado por parte dos editores por estar trabalhando no Brasil. O que acontece é que não havia muito cuidado com a seleção dos trabalhos que saiam nas revistas científicas brasileiras. Vejo que hoje a situação mudou e há muito mais profissionalismo neste campo em nosso país.
C Com um currículo tão rico, tendo passado por diferentes instituições e diversos países, trabalhado em tantas frentes que incluíram não somente a pesquisa básica e aplicada, como também o ensino de graduação e pós-graduação e a administração, que mensagem o senhor deixaria para o estudante, em início de carreira em pesquisa?

B Que façam alguma coisa que venha de dentro para fora. Que sejam puros.

\section{Referências}

1 Barbosa, F.S., 1949. Em torno de uma questão de nomenclatura botanica medica: Paracoccidi oides brasiliensis (Splendore, 1912) Almeida, 1930, o agente etiologico da forma brasileira da "Blastomycose" (Granuloma Paracoccidioidico). Jornal de Medicina dePernambuco, 36:429-445.

2 Pellon, A.B. \&Teixeira, I., 1950. Distribuição da Esquistossomose mansônica no Brasil. Monografia da Divisão de Organização Sanitária, Rio de Janeiro: Ministério da Saúde.

3 Olivier, L. \& Barbosa, F.S., 1956. Observations on vectors of schistosomiasis mansoni kept out of water in the laboratory. II. Journal of Parasitology, 42:277-286 e Barbosa, F.S. \& Barbosa, I., 1958. Dormancy during the larval stages of the trematode Schistosoma mansoni in snails estivating on the soil of dry natural habitats. Ecology, 39:763-764.

4 Barbosa, F.S., 1973. Possible competitive displacement and evidence of hybridization between two Brazilian species of planorbid snails. Malacologia, 14:401-408.

5 Barbosa, F.S.; Costa, D.P.P. \& Arruda, F., 1983. Competitive displacement between species of freshwater snails. I. Laboratory. 1a. General methodology. Memórias do Instituto Oswal do Cruz, 78:335-341 e Barbosa, C.S.; Barbosa, F.S \& Arruda, F., 1993. Controlled field experiment on the competition between two species of Biomphalaria, the snail vectors of Schistosoma mansoni in Northeastern Brazil. Cadernos deSaúde Pública, 9:85-89. 
6 Barbosa, F.S.; Carneiro, E. \& Barbosa, I., 1961. Notes on the morphology and taxonomy of the planorbid snail Biomphalaria pfeifferi (Krauss) from south-east Africa. Annals of Tropical Medicineand Parasitology, 55:242-248.

7 Barbosa, F.S.; Hubendick, B.; Malek, E.T.A. \& Wright, C.A., 1961. The generic names Austral orbis, Biomphalaria, Platytaphius, Taphius (Mollusca, Planorbidae). Annals and Magazine of Natural History, 4(ser.13):371-375.

8 Barbosa, F.S.; Pinto, R. \& Souza, O.A., 1971. Control of schistosomiasis mansoni in a small north east Brazilian community. Transactions of the Royal Society of Tropical Medicine and Hygiene, 65:206-213.

Barbosa, F.S. \& Costa, D.P., 1981. A long-term schistosomiasis control project with molluscicide in a rural area of Brazil. Annals of Tropical Medicineand Parasitology, 75:41-52.

10 Barbosa, F.S., 1965. Morbidade na Esquistossomose. Estudo em Quatro Localidades no Estado de Pernambuco. Recife: Faculdade de Medicina, Universidade do Recife. [também publicado na Revista Brasileira de Malariologia eDoenças Tropicais, 3(número especial):3-159].

11 Barbosa, F.S., 1981. Incapacitating effects of schistosomiasis mansoni on the productivity of sugarcane cutters in northeastern Brazil. American Journal of Epidemiology, 114:102-111 e Costa, D.P.P. \& Barbosa, F.S., 1980. Esquistossomose em trabalhadores da Usina Catende, Pernambuco, Brasil. Revista de Saúde Pública, 14:469-474.
12

Gilles, H.M.; Zaki, A.A.; Soussa, M.H.; Samaan, S.A.; Soliman, S.S.; Hassan, A. \& Barbosa, F.S., 1973. Results of a seven year snail control project on the endemicity of Schistosoma haematobium infection in Egypt. Annals of Tropical Medicine and Parasitology, 67:45-65.

13 Barbosa, F.S., 1977. Atenção à saúde e educação médica: uma experiência e uma proposição. Educación Médica y Salud, 2:26-37; Barbosa, F.S., 1978. Educação médica em programa de extensão. Revista Brasileira de Educação Médica, 2:9-16 e Barbosa, F.S. \& Santana, J.F.N.P., 1976. Regionalização docente-assistencial. O Projeto Planaltina. In: Anais, VI Conferência Pan-Americana de Educação Médica e XIV Congresso Brasileiro de Educação M édica, pp. 203-212. Rio de Janeiro: ABEM.

14 Barbosa, F.S., 1979. Aspectos epi demiológicos da reprodução humana. II. O estudo de Planaltina. Revista da Fundação SESP, 24:19-30 e Barbosa, F.S. \& Coimbra Jr., C.E.A., 1979. Esquistossomose mansônica autóctone no Distrito Federal, Brasil. Revista de Saúde Pública, 13:108-112.

15 Almeida, I.S., 1979. Estudo Clínico e Epidemiológico da Giardíaseem Crianças de Um a DozeAnos do Bairro Nossa Senhora de Fátima, Planaltina, DF. Tese de Mestrado, Brasília: Faculdade de Ciências da Saúde, Universidade de Brasília e Santana, J.F.N.P., 1980. Estudo sobrea atenção à saúde infantil no Programa Planaltina. Tese de Mestrado, Brasília: Faculdade de Ciências da Saúde, Universidade de Brasília.

16 Barbosa, F. S., 1980. Programa Integrado de Saúde Comunitária: Uma História deCaso. Brasília: CNPq. 